\title{
Genetic Diversity Analysis of Pleurotus spp. in Himachal Pradesh Using RAPD Fingerprints
}

\author{
Rishu Sharma*, B.M. Sharma and P.N. Sharma \\ Department of Plant Pathology, CSKHPKV, Palampur, H. P- 176062, India \\ *Corresponding author
}

Keywords

Pleurotus, RAPD, UPGMA, Tissue culture, Scoring

Article Info

Accepted:

17 June 2018

Available Online:

10 July 2018
A B S T R A C T

Random amplified polymorphism DNA (RAPD) analysis was done to assess the diversity among 21 species/strains of Pleurotus. The morphologically similar species/ strains too gave a new account of the evolutionary process and taxonomy of mushrooms. A total of 15010 mer primers were screened, out of which 10 primers viz. OPD-03, OPD-05, OPD08, OPA-13, OPA-16, OPQ-15, OPQ-16 and OPQ-18, S-1461 and S-1462 produced consistent polymorphic banding pattern. The RAPD dendogram obtained by Unweighted Pair Group Method with Arithmetic Mean (UPGMA) programme revealed a high genetic diversity among the isolates of Pleurotus. Twenty one isolates were divided into three clusters using 16 per cent similarity as a cut-off point. The cluster I accommodated 17 isolates of different species, whereas cluster III contained one strain of $P$. fossulatus I (P8) and two strains of Pleurotus sp. III (P15) and Pleurotus sp. IV (P18). RAPD bands were scored as present (1) or absent (0) for all the Pleurotus isolates. Each band was assumed to represent a unique genetic locus. The pattern and extent of RAPD variation were analysed with respect to primer, polymorphic locus and isolate. Total number of amplified fragment and polymorphic fragment produced by 10 decamer primer was 141 and 109, respectively with a polymorphism percentage of 77.30.

\section{Introduction}

Representatives of genus Pleurotus form a heterogeneous group of edible species of high commercial importance (Zervakis et al., 2004). However, there are many problems in taxonomy of Pleurotus spp. which are still unresolved. The concept of naming species on the basis of morphological characteristics has been dominant in the fungal taxonomy. However, morphological features of higher fungi are inconsistent as they are strongly influenced by cultivation substrate and environmental conditions (Bresinsky et al., 1976). Consequently, different taxonomists have given different concepts and conclusions for the same taxon on the basis of morphological features.

According to Zervakis and Balis (1996), taxonomic confusion in Pleurotus spp. has mainly been due to initial misidentification, absence of type specimens and instability of morphological characters due to environmental changes. In the recent years, biochemical, molecular techniques and mating 
compatibility tests have been used to solve the taxonomic problems within genus Pleurotus.

Molecular markers being enormous in number have a property of not being affected by the environment; make them a useful tool for understanding phylogenetic relationships as well as taxonomic identification. Molecular phylogenetic studies in mushrooms have been largely based on Restriction fragment length polymorphism (RFLP) and Random amplified polymorphic DNA (RAPD). DNA fingerprinting offers reproducible and reliable genetic differentiation of isolates into species and their strains (Braithwaite, 1989; Monastyrskii et al., 1990). Khush et al., (1992) studied DNA amplification polymorphism in Agaricus bisporus and identified seven distinct genotypes among eight heterotrophic strains using RAPD markers. But, very less amount of such work has been done in Pleurotus in North western Himalayan region s of India. Thus the present study was proposed with the objective of Pleurotus species/ strain identification using RAPD markers.

\section{Materials and Methods}

\section{i) Collection, isolation and maintenance of pure culture}

Various species/strains of Pleurotus were collected/procured from different sources. Majority of the species/strains were collected from the natural habitat during surveys conducted in different localities of Himachal Pradesh during monsoon months. Some of the species were procured from NRCM Solan.

Isolations from the fresh specimen, collected from the wild were made following the standard tissue culture technique (Gamborg, 2002). The stock cultures were maintained in the refrigerator at $4^{\circ} \mathrm{C}$. Sub-culturing of the stock cultures was done after a period of 7-10 days on fresh Yeastal Potato Detrose Agar slants (Table 1).

\section{Molecular characterization}

\section{Extraction of genomic DNA}

Total genomic DNA of each isolate was extracted following the standard procedure (Sharma et al., 2005). The amount of DNA was quantified by recording the absorbance at $260 \mathrm{~nm}$ wavelength using UV/VIS Spectrophotometer (BioRad Smart Spec 3000). DNA was stored at $-20^{\circ} \mathrm{C}$ for further use.

\section{Assessment of genetic diversity by RAPD analysis}

Random amplified polymorphic DNA (RAPD) based fingerprinting was used to study variation in Pleurotus species/strains.

\section{Primer screening}

One hundred and fifty 10 -mer primers (Operon Technologies Inc. Almedea, USA and Life Technologies, India Pvt. Ltd.) were screened twice with two randomly selected isolates of Pleurotus to select primers showing maximum polymorphism with consistent banding pattern. Ten most polymorphic and reproducible primers viz. OPD-03, OPD-05, OPD-08, OPA-13, OPA-16, OPQ-15, OPQ16, OPQ-18, S-1461 and S-1462 were finally used in RAPD analysis.

\section{PCR amplification}

The PCR amplification was carried out in 0.2 $\mathrm{ml}$ PCR tubes with $25 \mu \mathrm{l}$ reaction volume containing $2.5 \mu \mathrm{l}$ of $10 \mathrm{x}$ buffer $(20 \mathrm{mM}$ Tris $\mathrm{HCl}, \mathrm{pH} 8.0,50 \mathrm{mM} \mathrm{KCl}) ; 1.5 \mu \mathrm{l}$ of $\mathrm{MgCl}_{2}$ (25 mM $\mathrm{MgCl}_{2}$ ), $2.0 \mu \mathrm{l}$ of dNTP's (2.5 mM each) (Eppendorf, India Pvt. Ltd.), $1.0 \mu \mathrm{l}$ primer, $0.2 \mu \mathrm{l}$ of Taq polymerase (Bangalore 
Genei, India, $5 \mathrm{U} / \mu \mathrm{l}), 2 \mu \mathrm{l}$ of DNA template and $15.8 \mu \mathrm{l}$ of sterilized distilled water to make total reaction volume of $25 \mu$. Reaction mixture was vortexed and centrifuged in a microfuge (Bangalore Genei, India) for the proper mixing of the contents. Amplifications were performed using thermal cycler (Gene Amp PCR System 9700, Applied Biosystems, USA) programmed with initial denaturation at $94^{\circ} \mathrm{C}$ for 5 minutes, followed by 40 cycles at $94^{\circ} \mathrm{C}$ for 1 minute, $37^{\circ} \mathrm{C}$ for 1 minute, $72^{\circ} \mathrm{C}$ for 2 minutes and a final extension at $72^{\circ} \mathrm{C}$ for 5 minutes.

\section{Gel electrophoresis}

The amplified PCR products were resolved by electrophoresis using 1.2 per cent agarose gel in $0.5 \mathrm{X}$ Tris borate EDTA buffer $(0.5 \mathrm{M}$ Tris, $0.05 \mathrm{M}$ boric acid and $1 \mathrm{mM}$ EDTA, $\mathrm{pH}$ 8.0). The gels were stained with $0.5 \mu \mathrm{g} / \mathrm{ml}$ of Ethidium bromide. 100 bp DNA ladder (Biobasic, Lifetech, India Pvt. Ltd.) and lambda DNA / EcoR / Hind III double digest (MBI Fermentas) were used as markers. The gels were run at $80 \mathrm{~V}$ for two hours (Bangalore Genei System) and were viewed under the gel documentation system (AlphaImager 2200, Alpha Infotech Corporation, and USA) and scored.

DNA bands that could be scored univocally for presence (1) and absence (0) were included in analysis. Binary matrices were analysed by NTSYS pc V 2.0 (Rholf, 1998) and Jaccard's coefficient was used to construct dendrogram using SHAN clustered programme, selecting the unweighted pair group arithematic mean (UPGMA). The dendrogram with best fit for to similarity matrix based on cophentic value $(\mathrm{COPH})$ and matrix comparison (MXCOMP) was chosen.

\section{Results and Discussion}

DNA based markers have increased the potential to study the genetic diversity of various fungal isolates of same or different species, as these markers are not affected by the environment. In the present study, RAPD markers were used to determine the genetic diversity among Pleurotus isolates. RAPD analysis revealed the existence of high genetic diversity among 21 Pleurotus isolates. Cluster analysis of RAPD data divided test isolates into three major and five sub-clusters.

\section{RAPD analysis of Pleurotus species/strains}

Random amplified polymorphic DNA (RAPD) based fingerprinting was used to study variation in Pleurotus species/strains. Initially 150 primers were used for the amplification of two randomly selected isolates of Pleurotus with a view to screen primers exhibiting maximum polymorphism.

Ten 10-mer primers viz. OPD-03, OPD-05, OPD-08, OPA-13, OPA-16, OPQ-15, OPQ-16 and OPQ-18 (Operon Technologies Inc. Almedea, USA), S-1461 and S-1462 (Life Technologies, India Pvt. Ltd.) produced consistent polymorphic banding pattern with 11-17 bands of 0.3-3.0 kb (Table 2). Finally these 10 primers were used for RAPD analysis of 21 Pleurotus species/strains.

The number of scorable and polymorphic bands obtained with each primer ranged from 11-17 and 9-14, respectively (Table 2). The maximum polymorphism was found with primer OPD-05 (87.5\%) followed by S-1462 (85.71\%), S-1461 (81.81\%) and OPQ-16 (80.00\%). Among 141 scorable bands, 109 were polymorphic with 77.30 per cent polymorphism.

Cluster analysis of scorable RAPD bands generated a dendrogram revealing high genetic diversity in Pleurotus species/strains. Twenty one isolates were divided into three clusters using 16 per cent similarity as a cutoff point. 
Table.1 Source of collection of various Pleurotus species / strains

\begin{tabular}{|c|c|c|}
\hline SOURCE & NAME & SPECIES /STRAINS \\
\hline Collection from wild & $\begin{array}{l}\text { P11 } \\
\text { P5 } \\
\text { P21 } \\
\text { P3 } \\
\text { P4 } \\
\text { P12 } \\
\text { P6 } \\
\text { P8 } \\
\text { P10 } \\
\text { P18 } \\
\text { P19 } \\
\text { P20 } \\
\text { P7 } \\
\text { P15 } \\
\text { P17 }\end{array}$ & $\begin{array}{l}\text { Pleurotus sp.II } \\
\text { Pleurotus cystidiosus I } \\
\text { Pleurotus ostreatus IV } \\
\text { Pleurotus flabellatus II } \\
\text { Pleurotus cornucopiae } \\
\text { Pleurotus cystidiosus II } \\
\text { Pleurotus pulmonarius } \\
\text { Pleurotus fossulatus I } \\
\text { Pleurotus fossulatus II } \\
\text { Pleurotus } s p . \mathrm{IV} \\
\text { Pleurotus } s p . \mathrm{V} \\
\text { Pleurotus ostreatus III } \\
\text { Pleurotus sp.I } \\
\text { Pleurotus sp.III } \\
\text { Pleurotus eryngii II }\end{array}$ \\
\hline NRCM, Solan & $\begin{array}{l}\text { P1 } \\
\text { P2 } \\
\text { P9 } \\
\text { P13 } \\
\text { P14 } \\
\text { P16 }\end{array}$ & $\begin{array}{l}\text { Pleurotus sapidus } \\
\text { Pleurotus flabellatus I } \\
\text { Pleurotus florida } \\
\text { Pleurotus ostreatus I } \\
\text { Pleurotus eryngii I } \\
\text { Pleurotus ostreatus II }\end{array}$ \\
\hline
\end{tabular}

Table.2 Number of scorable and polymorphic RAPD bands obtained by PCR amplification of DNA of Pleurotus species/strains with primers showing polymorphism

\begin{tabular}{lccc}
\hline Primers & Scorable bands & Polymorphic bands & Per cent polymorphism \\
\hline OPD-03 & 17 & 12 & 70.5 \\
OPD-05 & 16 & 14 & 87.5 \\
OPD-08 & 14 & 10 & 71.4 \\
OPA-13 & 13 & 10 & 76.92 \\
OPA-16 & 14 & 10 & 71.42 \\
OPQ-15 & 12 & 9 & 75.00 \\
OPQ-16 & 15 & 12 & 80.00 \\
OPQ-18 & 15 & 11 & 73.33 \\
S-1461 & 11 & 9 & 81.81 \\
S-1462 & 14 & 12 & 77.30 \\
Total & $\mathbf{1 4 1}$ & $\mathbf{1 0 9}$ & $\mathbf{7 7 . 3 0}$ \\
\hline
\end{tabular}




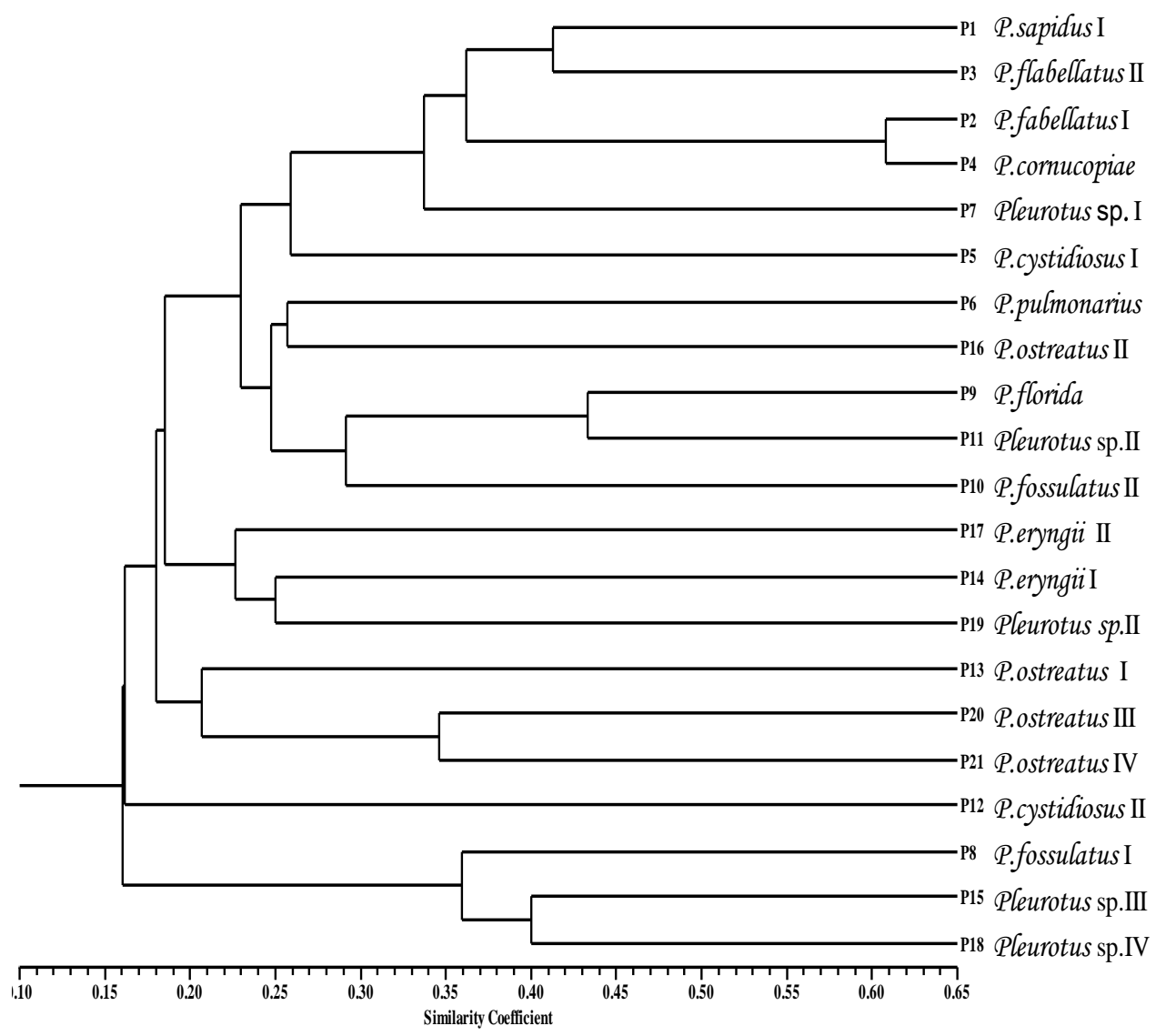

FIG. 4.1 : Dendrogram of 21 isolates of Pleurotus spp. generated by UPGMA ( Unweighted pair group method arithmetic mean) analysis with 10 RAPD primers.

The cluster I accommodated 17 isolates of different species, whereas cluster III contained one strain of $P$. fossulatus I (P8) and two strains of Pleurotus sp. III (P15) and Pleurotus sp. IV (P18). Besides this cluster II possessed only one strain of $P$. cystidiosus (P12) as shown in figure 1 . The cluster I was sub-divided into two sub-clusters $\mathrm{I}_{\mathrm{a}}$ and $\mathrm{I}_{\mathrm{b}}$ at 18 per cent similarity. The sub-cluster $I_{a}$ included 14 isolates and sub-cluster $\mathrm{I}_{\mathrm{b}}$ contained three strains of $P$. ostreatus (P13, P20 and P21) (Fig. 1). However, RAPD was unable to differentiate the various Pleurotus species into distinct clusters. There was no congruence between RAPD and morphological groupings of the test isolates.
Similar diversity in different Agaricales including Pleurotus has also been reported by many workers (Khush et al., 1992; Liu et al., 1995; Singh et al., 2000; Lewinsohn et al., 2001). Singh et al., (2000) observed wide variation among different genera of Agaricales and also within Pleurotus species and strains using RAPD analysis. Lewinsohn et al., (2001) observed 68 and 32 per cent genetic diversity in twelve populations (144 isolates) of Pleurotus eryngii using RAPD markers. However, Stajic et al., (2005) categorized 37 strains of ten Pleurotus species using RAPD into six clusters and concluded that morphology does not necessarily coincide genetics. In our study, 10 mer primers OPD- 
03 and OPA-13 amplified a distinct $500 \mathrm{bp}$ fragment in all the isolates of Pleurotus cystidiosus and $P$. eryngii. Whereas $2350 \mathrm{bp}$ fragment was noticed only in P. ostreatus II isolate with primer OPA-16, thus differentiating them from other species/strains. Similar distinction of Pleurotus species using RAPD fingerprint has also been reported by Marongiu et al., (2001) who found a 1200 bp fragment only in $P$. eryngii samples collected from host plant Ferula communis but not in those collected from Eryngium species. However, Lee et al., (2000) observed a $600 \mathrm{bp}$ fragment in all $P$. ostreatus isolates using RAPD markets.

\section{Acknowledgement}

Authors are grateful to National Horticultural Board for the financial assistance and Molecular Plant Pathology Laboratory, CSKHPKV, Palampur, for cooperating us in conducting this experiment.

\section{References}

Braithwaite, K,S., Manners, J.M (1989). Human hypervariable minisatellite probes detect DNA polymorphisms in the fungus Colletotrichum gloeosporioides. Current Genetics 16: 473- 475.

Bresinsky, A., Hilber, O., Molitoris, H. P. (1976). The genus Pleurotus as an aid for understanding the concept of species in Basidiomycetes. In: The species concept in Hymenomycetes. (ed. Clemenson H) Cramer, Vadiz, pp. 229-258.

Gamborg, O.L. (2002). Plant tissue culture. Biotechnology. Milestones. In Vitro Cellular \& Developmental Biology. 38(2): 84-92.

Khush, R.S., Becke, E. and Wach, W. (1992). DNA amplification polymorphisms of the cultivated mushroom Agaricus bisporus. Applied and Environmental Microbiology 58 (9): 2971-2977.

Lee, H.K., Shin, C.S., Min, K.B., Choi, K.S., Kim, B.G., Yoo, Y.B. and Min, K.H.(2000). Molecular systematics of the genus Pleurotus using sequence specific oligonucleotide probes. Science and Cultivation of Edible fungi. Proceedings of the 15 th International Congress on the Science and Cultivation of edible Fungi, Maastrict, Netherlands, 15-19. May. 207-213

Lewinsohn, D., Nevo, E., Wasser, S.P., Hadar, Y. and Beharav, A.(2001). Genetic diversity in populations of the Pleurotus eryngii complex in Israel. Mycological Research 105 (8): 941951.

Liu, G., Liu, Z., Lia, J., Liu, L., Tai, L., Li, X., Zhu, H. and Zhu, L (1995). Studies on fusants derived from intergeneric protoplast fusion of Pleurotus sapidus and Lentinus edodes by RAPD analysis. Hereditas- Beijing 17(5): 37 40.

Marongiu, P., Corda, P., Maddau, L., Rosa, V.D., Reverberi, M.and Marras, F (2001). Molecular characterization of the population Pleurotus eryngii (DC:Fr.) Quel. Bollettino-dellAssociazione-Micologica-edEcologica-Romana 52/53: 3-8.

Monastyrskii, O.A., Ruban, D.N., Tokarskaya, O.N. and Ryskov, A.P (1990). DNA fingerprints of some Fusarium isolates differentiated toxicogenically. Genetika 26: 374377.

Rholf, F.J. (1998). NTSYS-pc: Numerical Taxonomy and Multivariate Analysis System version 2.0. Exter Software: Setauket, New York.

Sharma, P.N., Kaur, M., Sharma, O.P., Sharma, P. and Pathania, A (2005). Morphological, Pathological and 
Molecular Variability in Colletotrichum capsici, the cause of Fruit Rot of Chillies in the subtropical Region of North-Western India. Phytopathology 153: 232-237.

Singh, S.K., Rana, M.K. and Verma, R.N. (2000).

Amplified polymorphisms of cultivated mushrooms. Mushroom Research 9(1): 19-25.

Stajic, M., Sikorski, J., Wasser, S.P. and Nevo, E. (2005). Genetic similarity and taxonomic relationships within the genus Pleurotus (higher
Basidiomycetes) determined by RAPD. Mycotaxon 93: 247-255.

Zervakis, G., Sourdis, J. and Balis, C. (1994). Genetic variability and systematics of eleven Pleurotus species based on isozyme analysis. Mycological Research. 98: 329-341.

Zervakis, G. I., Monslavo, J. M. and Vilgalys, R (2004). Molecular phylogeny, biogeography and speciation of the mushroom species Pleurotus cystidiosus and allied taxa. Microbiology 150: 715-726.

\section{How to cite this article:}

Rishu Sharma, B.M. Sharma and Sharma, P.N. 2018. Genetic Diversity Analysis of Pleurotus spp. in Himachal Pradesh Using RAPD Fingerprints. Int.J.Curr.Microbiol.App.Sci. 7(07): 2148-2154. doi: https://doi.org/10.20546/ijcmas.2018.707.253 